\title{
CHANGES IN HEAD \& SHOULDER POSTURE OF COLLEGIATE STUDENTS CARRYING LAPTOP BAG AS SIDE PACK
}

\section{Siddhartha Sen $* 1$, Ajita D Singh ${ }^{2}$.}

*1 Research Scholar PhD, Punjabi University, Patiala, Punjab, India.

${ }^{2}$ Associate Professor, Punjabi University, Patiala, Punjab, India.

\section{ABSTRACT}

Introduction: Backpack carriage is common among adults, schoolchildren and adolescents for daily transferring of personal belongings, laptops, books and stationeries to and from offices, colleges or schools. As the load of backpack is directly applied to the spine via the shoulder straps and external loading has been demonstrated to be associated with spinal disorders.

Purpose of the study: is to find out the changes in head posture $\&$ shoulder by 2D method in collegiate student with backpack and side pack.

Materials and Methods: 105 subjects collegiate student were recruited to measure the head posture. Photograph of the cervicothoracic region were taken from side to measure craniovertebral angle and sagittal shoulder posture with loaded right side pack and left side pack.

Results: Comparison between individuals with side pack and without any pack in craniovertebral angle and sagittal shoulder posture was done using pared sample $t$ test and the result showed significant differences. When comparison was done between different pack the results showed significant between back pack \& right side pack and back pack \& left side pack.

Conclusions: The subjects who were carrying load in side pack for prolonged past duration and presently 2 hours per day have decreased craniovertebral angle and produces forward head posture when compared with no pack and sagittal shoulder angle increases which produces rounded shoulder posture.

KEY WORDS: Side pack, craniovertebral angle, sagittal shoulder posture, musculoskeletal disorders.

Address for correspondence: Dr. Siddhartha Sen. PT., Research Scholar PhD, Punjabi University, Patiala, Punjab, India. E-Mail: siddhartha.pt@gmail.com

\begin{tabular}{|c|c|c|}
\hline \multicolumn{3}{|c|}{ Access this Article online } \\
\hline 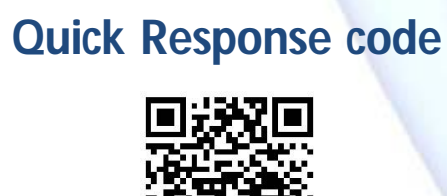 & \multicolumn{2}{|c|}{$\begin{array}{l}\text { International Journal of Physiotherapy and Research } \\
\text { ISSN 2321- } 1822 \\
\text { www.ijmhr.org/ ijpr.html }\end{array}$} \\
\hline Dol: 10.16965 /ijpr.2016.199 & $\begin{array}{l}\text { Received: 27-11-2016 } \\
\text { Peer Review: 28-01-2016 } \\
\text { Revised: None }\end{array}$ & $\begin{array}{l}\text { Accepted: 20-12-2016 } \\
\text { Published (0): 11-02-2017 } \\
\text { Published (P): 11-02-2017 }\end{array}$ \\
\hline
\end{tabular}

\section{INTRODUCTION}

Backpack carriage is common among adults, schoolchildren and adolescents for daily transferring of personal belongings, laptops, books and stationeries to and from offices, colleges or schools. As the load of backpack is directly applied to the spine via the shoulder straps and external loading has been demonstrated to be associated with spinal disorders [1]. De Paula et al. [2] found that a significant number of students carry backpacks weighing more than
$10 \%$ of their BWs most of the time. This heavy stress puts the student at an increased risk of injury [3].

Total weight carried, duration and frequency of carriage and the manner in which the weight is carried all affect the demands on the musculoskeletal system and may affect the incidence of musculoskeletal pain or discomfort. The improper use of backpacks can lead to muscle imbalance that could turn into chronic pain and neck problems later on during the lifetime. In a 
study conducted by Grimmer et al. [4] of 1269 high school students in Adelaide, Australia, found gender and age specific associations between recent low back pain, the amount of time spent sitting, the backpack load and the time spent carrying it. Backpack carried by collegiate students and their role in the development of musculoskeletal pain has been the subject of recent attention [5] and reducing backpack weight has been suggested as one prevention strategy to reduce hiking-related injury [6] with previous research recommending $30 \%$ body weight (BW) as the maximum load for healthy adult males. [7] if it is necessary to carry loads more than $10 \%$ of body weight, the modified backpack helps the integrity of the back and neck. Also, it helps to reduce muscular stresses on the back when the backpack exceeds the lifted weight of $10 \%$ of student's BW. Therefore, the use of the modified backpack is better than to use the commercial one [8].

As proprioception is essential for the normal control of human movement [9], any proprioceptive deficit would increase the potential risk of injury. All innervated structures, including muscles, tendons, ligaments, joints and skin, are the sources of proprioceptive input (M atthews, 1988) [10]. The change in proprioception could be quantified by measuring the changes in movement sense and position sense [9].

The use of information technology in all areas of life is rapidly increasing, and this is particularly evident within the school system. India is pioneering the use of laptop computers within the school environment, particularly within the private education system. Additionally, laptop computers are one of the fastest growing trends in the world of business today and currently the single largest growth area within the personal computer market.

It is evident that a lot of research work has been done related to back pack and scapular kinematics but there is a paucity of research linking the involvement with side pack. Thus there is purpose of the study to find out the changes in head posture $\&$ shoulder by 2D method in collegiate student with side pack.

\section{MATERIALS AND METHODS}

Participants: 105 subjects collegiate student form Sardar Bhagwan Singh (PG) Institute of Biomedical Sciences \& Research, Balawala, Dehradun were conveniently recruited in this study. The detailed protocol of the research was explained and consent of every subject was taken prior to their inclusion in the study. The whole research was approved by the human subjects ethics review committee at the Punjabi University, Patiala, India. A brief questionnaire was used to identify any history of shoulder pathology, as well as primary activities of daily living that involved overhead activity. Those who reported a history of shoulder pathology or were currently experiencing shoulder pain, and thoracic spine pain were excluded from the study. Each subject has to undergone the palpation of anatomical landmarks and the marker was attached. Photographs were taken first without carrying any pack after that they were instructed to go for treadmill walking with right side pack and left side pack. Subject has to walk for 20 minutes at a speed of 4-5km / hour. After that a second session of photography was introduce to take photograph from side with the load.

Measurement of Head \& shoulder posture: A Custom made single-strap side pack was used in this study. The side pack carries $4 \mathrm{kgs}$ of weight with standard laptop and books. The lengths of the backpack straps were adjusted according to the participant's comfort at the beginning of the experiment to minimize the effect on the pulmonary function [11].

After the physical examination, the initial head posture of the participant without carrying any load was measured as the baseline with photographic method. Subsequently, the participant was asked to walk with side pack carriage on a motor driven treadmill for 20 min [3] with walking speed set at approximately $1.1 \mathrm{~m} / \mathrm{s}$ or $4 \mathrm{~km} /$ hr. [12] The side pack was removed after the 20-min loaded walking. Postural measurements were conducted immediately after the treadmill walking with the side pack load.

Head posture was measured using photographic method where bony landmark identified and marked with marker which is red colored bindi and a digital photograph were taken by using Nikon digital SLR camera. Accuracy of the investigator's surface landmark was confirmed by two assistant professors of Physiotherapy. 
The palpation and marking was carried out in the same standing position as the subject would later adopt for the photographs, to reduce any error that might have occurred from skin movement [13]. For the measurement of the head posture and shoulder posture, 5 adhesive markers (12 $\mathrm{mm}$ in diameter) were placed on the following anatomic points: tragus of right and left ear, spinous process of the seventh cervical vertebra (C7) posterior angle of the right and left acromion [14].

The subject stood with feet shoulder-width apart and arms at the sides. Subjects were instructed to place their heels on a line on the floor and extend their arms with the hand open. To measure scapular kinematics, two photographs of the cervicothoracic region one from left side with left side pack and other from right side with right side pack was then taken. Nikon digital SLR camera (M anufactured by Nikon Corporation, Japan) with a $18-105 \mathrm{~mm}$ adjustable Zoom lens was used to take photograph. The camera was placed $4 \mathrm{~m}$ from the subject and mounted on a 62 inch tripod (M anufactured by Dolika) and leveled with a bubble spirit level to control frontal and sagittal angles.[15] The lens aperture was set at Fstop 8 and was zoomed to $50 \mathrm{~mm}$ for the front and side photograph. Subjects were placed so that the centre of the lens was four meters away from the subject, and camera was positioned perpendicular to the ground and parallel to the facing plane of the subject. The height of the cameras was adjusted to be approximately level with the neck of the subject. The positioning of the camera minimized parallax error and placed the subject approximately in the centre of the lens so as to minimize lens error [13]. The entire photograph was imported in Corel draw software to draw the angle.

1. Forward head position (F-Head): is the anterior movement of the cervical spine projecting the head forward. The measurement of forward head position was obtained from the angle formed by the intersection of a straight line passing through the reflective marker on the tragus of the ear and $\mathrm{C} 7$ and a straight horizontal line intercepting $\mathrm{C} 7$ on the sagittal plane. This angle describes the position of the head in relation to $\mathrm{C7}$ [16].

2. Protrusion of the shoulders (P-Shoul): correInt J Physiother Res 2017;5(1):1824-28. ISSN 2321-1822 sponds a more anteriorized posture of the shoulders. The protrusion angle was obtained from the intersection of a straight line passing through the posterior angle of the acromion and $\mathrm{C} 7$ with a straight horizontal line intercepting the posterior acromion on the sagittal plane. An increased angle indicates that the shoulder is projected forward in relation to C7 [16].

Fig. 1: Measurement of head and shoulder posture.

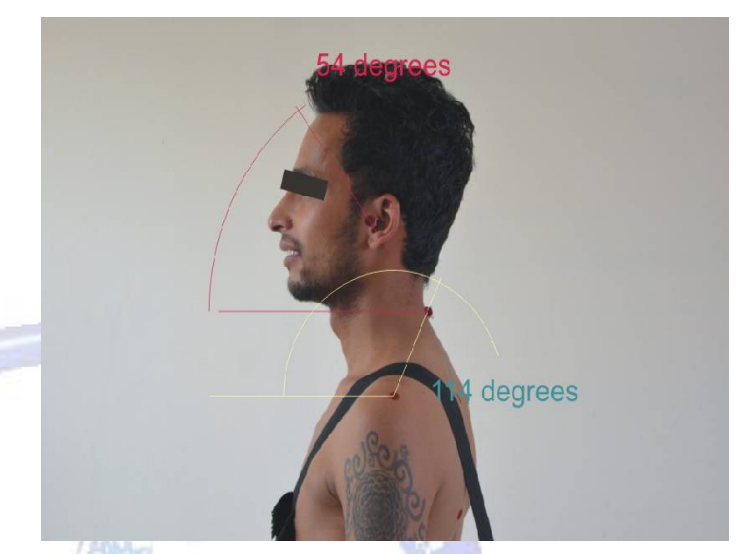

\section{DATA ANALYSIS AND RESULT}

The data was analyzed using statistical tests which were performed using SPSS 11.0 software package. when Comparison was done between individuals with different pack, a pared sample $t$ test was used and the result showed significant differences in comparison between right side pack $\&$ without any pack and left side pack $\&$ without any pack and showed insignificant when compared between right side pack $\&$ left side pack (Table 3). For protruded shoulder, the result showed significant differences in comparison between right side pack $\&$ without any pack and left side pack $\&$ without any pack and insignificant differences when compared between left side pack \& left side pack (Table 4 ).

Table 1: M ean \& Standard Deviation of Craniovertebral angle in individuals with different Packs.

\begin{tabular}{|c|c|c|c|}
\hline & Mean & SD & SEM \\
\hline Right Side Pack & 44.6 & 3.04 & 0.2969 \\
\hline Left Side Pack & 45.18 & 2.52 & 0.2461 \\
\hline Without any pack & 53.67 & 1.74 & 0.1696 \\
\hline
\end{tabular}

Table 2: M ean \& Standard Deviation of Sagittal Shoulder Posture individuals with different packs.

\begin{tabular}{|c|c|c|c|}
\hline & Mean & SD & SEM \\
\hline Right Side Pack & 120.43 & 8.924 & 0.8709 \\
\hline Left Side Pack & 120.67 & 9.365 & 0.914 \\
\hline Without any pack & 108.51 & 4.713 & 0.4599 \\
\hline
\end{tabular}


Table 3: Comparison between individuals with different pack and without any pack in Craniovertebral angle.

\begin{tabular}{|c|c|c|c|c|}
\hline & SEM & t- value & p-value & Significant \\
\hline $\begin{array}{c}\text { Right Side Pack Vs } \\
\text { without any pack }\end{array}$ & 0.3504 & 25.89 & 0.0001 & $\mathrm{~S}$ \\
\hline $\begin{array}{c}\text { Left Side Pack Vs without } \\
\text { any pack }\end{array}$ & 0.3014 & 28.18 & 0.0001 & $\mathrm{~S}$ \\
\hline $\begin{array}{c}\text { Right Side Pack Vs Left } \\
\text { side Pack }\end{array}$ & 0.3608 & 1.61 & 0.11 & NS \\
\hline
\end{tabular}

Graph 1: Comparison between different pack and without any pack for craniovertebral angle.

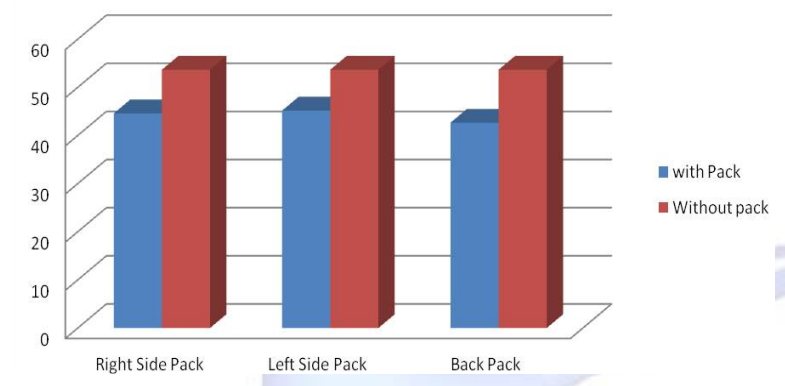

Table 4: Comparison between individuals with different pack and without any pack in Sagittal Shoulder Posture.

\begin{tabular}{|c|c|c|c|c|}
\hline & SEM & t- value & p-value & Significant \\
\hline $\begin{array}{c}\text { Right Side Pack Vs } \\
\text { without any pack }\end{array}$ & 0.9625 & 12.38 & 0.0001 & $\mathrm{~S}$ \\
\hline $\begin{array}{c}\text { Left Side Pack Vs } \\
\text { without any pack }\end{array}$ & 1.028 & 11.83 & 0.0001 & $\mathrm{~S}$ \\
\hline $\begin{array}{c}\text { Right Side Pack Vs } \\
\text { Left side Pack }\end{array}$ & 1.1021 & 0.21 & 0.829 & NS \\
\hline
\end{tabular}

Graph 2: Comparison between with pack and without any pack for sagittal shoulder angle.

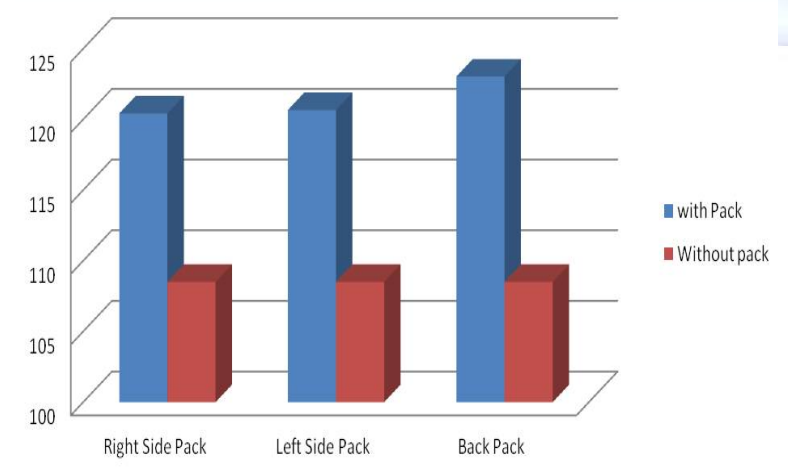

\section{DISCUSSION}

The subjects who are carrying load in any type of pack for prolonged past duration and presently 2 hours per day may have changed FHP and protruded shoulder. So when Comparison was done between individuals with different pack, the result showed significant differences in right side pack $\&$ without any pack and left side pack $\&$ without any pack. That means if collegiate student carries packs by means side pack the Craniovertebral angle decreases when compared with no pack thus produces forward head posture. For protruded shoulder, the result showed significant differences when compared between side pack with no pack.

This supports the finding of Pascoe et al. [17] who reported a forward lean of the head when carrying a backpack over both shoulders. When carrying load on side pack the body leans opposite side to compensate the load leads to changes of normal posture and to maintain balance while walking the neck has to protrude forward slightly. This in long run produces forward head posture.

Pheasant [18] showed difference in neck flexion is estimated to result in a $9 \%$ change in torque around $\mathrm{C7}$. The apparently small posture difference therefore is clearly of importance in terms of load on neck tissues. Kolehmainen et al. [19] found a similar relationship between neck flexion and load. Continuing work by the main author is investigating the effects on neck and shoulder musculature of such postural differences. Fiolkowski et al.[20] found that there were less hip flexion and forwards head position when the backpack was carried anteriorly. An anterior shift in the centre of gravity of the head elicits the head and neck postural reflexes involving the vestibulocollic [21], cervicocollic [22] and cervical-facet mechanoreceptors. These respond to the forward head position of the postural stimulation by actively orienting the trunk's centre of gravity under the head's centre of gravity [23]. Increased trunk flexion with increasing load has been identified as adaptation to bring the centre of gravity of the body and backpack further forward to maintain balance [24]. A significant trunk forward lean was reported for a load of $15 \%$ BW and above [25]. The use of a laptop computer instead of a desktop computer therefore appears to increase the stress around the user's neck and shoulders, and is likely to result in increased discomfort. Prolonged laptop use thus has a greater potential to lead to musculoskeletal disorders.

Based on previous research findings which showed increases in stiffness and pain in the neck with increased neck flexion it could be assumed that laptop users would experience increased discomfort due to this increased neck 
flexion [26]. Chansirinukor et al. [27] found a significantly decreased craniovertebral angle and a significantly increased sagittal shoulder posture angle at backpack load during standing and walking conditions. Williams GR et al. [28] also reported a significant change in the craniovertebral angle of the subjects carrying a backpack in a standing posture in five schoolyear stages compared with those who do not carry a backpack.

\section{CONCLUSION}

Based on results and analysis, it can be concluded that the subjects who were carrying load in side pack for prolonged past duration have decreased craniovertebral angle and produces forward head posture when compared with no pack and have the sagittal shoulder angle increases thus rounded shoulder posture arises.

\section{Conflicts of interest: None}

\section{REFERENCES}

[1]. Korovessis P, Koureas G, Zacharatos S, Papazisis Z. Backpacks, back pain, sagittal spinal curves and trunk alignment in adolescents: a logistic and multinomial logistic analysis. spine. 2005;30:247-55.

[2]. De Paula AJF, Silva JCP, Paschoarelli LC, Fujii JB. Backpacks and school children's obesity: challenges for public health and ergonomics. work. 2012;41(Suppl 1):900-6.

[3]. Mackie HW, Legg SJ, Beadle J, Hedderley D. Comparison of four different backpacks intended for school use. Applied Ergonomics. 2003;34:257-64.

[4]. Grimmer K, Williams MT, Gill TK. The Associations between Adolescent Head-on-Neck Posture, Backpack Weight, and Anthropometric Features. Spine. 1999;24(21):2261-7.

[5]. Javadivala Z, Allahverdipour H, Dianat I, Bazargan M. Awareness of parents about characteristics of a healthy school backpack. Health Promotion Perspectives. 2012;2:166-72.

[6]. M clntosh SE, Leemon D, Visitacion J, Schimelpfenig T, Fosnocht D. Medical incidents and evacuations on wilderness expeditions. Wilderness \& Environmental Medicine. 2007;18(4):298-304.

[7]. Haisman M F. Determinants of load carrying ability. Applied Ergonomics. 1988;19(2):111-21.

[8]. Mohamed Z. Ramadan, Al-Shayea AM. A modified backpack design for male school children. International Journal of Industrial Ergonomics. 2013;43:46271.

[9]. Swinkels A, Dolan P. Regional assessment of joint position sense in the spine. spine. 1998;23:590-7.

[10]. Matthews PB. Proprioceptors and their contribution to somatosensory mapping: complex messages require complex processing. Canadian journal of physiology and pharmacology. 1988;66:430-8.
[11]. Bygrave S, Legg SJ, Myers S, Llewellyn M. Effect of backpack fit on lung function. Ergonomics. 2004;47:324-9.

[12]. Hong Y, Li JX, Fong DT. Effect of prolonged walking with backpack loads on trunk muscle activity and fatigue in children. J Electromyogr Kinesiol. 2007.

[13]. Sally Raine, lance Twomey. Posture of the head, shoulders and thoracic spine in comfortable erect standing. Australian Journal of Physiotherapy. 1994:40:25-32.

[14]. Lewis J, Green A, Reichard Z, Wright C. Scapular position: the validity of skin surface palpation. M anual Therapy. 2002;7(1):26-30.

[15]. Raine S, Twomey LT. Head and shoulder posture variations in 160 asymptomatic women and men. Arch Phys Med Rehabil. 1997;78:1215-23.

[16]. Braun BL, Amundson LR. Quantitative assessment of head and shoulder posture. Arch Phys Med Rehabil. 1989;70(4):322-9.

[17]. Pascoe DD, Pascoe DE, Wang YT, Shim D-M, and Kim CK. Influence of carrying book bags on gait cycle and posture of youths. . Ergonomics. 1997;40:631-41.

[18]. Pheasant S. Bodyspace: Anthropometry, Ergonomics and Design. Iondon: Taylor \& Francis; 1986.

[19].Kolehmainen A, Harms-Ringdahl K, and Lanshammart $H$. Cervical spine positions and load moments during bicycling with different handlebar positions. Clinical Biomechanics. 1989;4:105-10.

[20]. Fiolkowski P, Horodyski M, Bishop M, Williams M, Stylianou $L$. Changes in gait kinematics and posture with the use of a front pack. Ergonomics. 2006;49(9):885-94.

[21]. W ilson VJ, Boyle R, Fukushima K, Rose PK, Shinoda Y, Sugiuchi $Y$. The vestibulocollic reflex. . Journal of Vestibular Research. 1995;5:147-70.

[22]. Peterson BW, Goldberg J, Bilotto G, Fuller JH. Cervicocollic reflex: its dynamic properties and interaction with vestibular reflexes. Journal of Neurophysiology. 1985;54:90-109.

[23]. M orningstar M, Strauchman M, Gilmour G. Idiopathic scoliosis treatment using the pettibon corrective procedures: A case report. Journal of Chiropractic Medicine. 2004;3:96-103.

[24]. Grimmer K, Dansie B, M ilanese S, Pirunsan U, Trott P. Adolescent standing postural response to backpack loads: a randomised controlled experimental study. BM C M usculoskeletal Disorders. 2002;3:10.

[25]. Hong Y, Cheung C. Gait and posture responses to backpack load during level walking in children. Gait and Posture. 2003;17:28-33.

[26]. Bendix T. Seated trunk posture at various seat inclinations, seat heights and table heights' Human Factors. 1986;26:695-703.

[27]. Chansirinukor W, Grimmer WK, Dansie B. Effects of Backpacks on Students: Measurement of Cervical and Shoulder Posture. The Australia Journal of Physiotherapy. 2001;47(2):110-6.

[28]. Williams GR, Shakil M, Klimkiewicz J. anatomy of the scapulothoracic articulation. Clin Orthop. 1999;359:237-46.

How to cite this article: Siddhartha Sen, Ajita D Singh. CHANGES IN HEAD \& SHOULDER POSTURE OF COLLEGIATESTUDENTSCARRYING LAPTOP BAG ASSIDE PACK. Int J Physiother Res 2017;5(1):1824-1828. DOI: 10.16965/ijpr.2016.199 